\title{
Power law distributions of wildfires across Europe: benchmarking a land surface model with observed data
}

\section{B. Di Mauro ${ }^{1}$, F. Fava ${ }^{1}$, P. Frattini ${ }^{2}$, A. Camia ${ }^{3}$, R. Colombo ${ }^{1}$, and M. Migliavacca ${ }^{4,1}$}

${ }^{1}$ Remote Sensing of Environmental Dynamics Laboratory, Earth and Environmental Sciences Department University of Milan-Bicocca, Milan, Italy

${ }^{2}$ Earth and Environmental Sciences Department University of Milan-Bicocca, Milan, Italy

${ }^{3}$ European Commission - Joint Research Centre (JRC), Institute for Environment and Sustainability, Ispra, Varese, Italy

${ }^{4}$ Biogeochemical Integration Department, Max Planck Institute for Biogeochemistry, Jena, Germany

Received: 22 October 2015 - Accepted: 13 November 2015 - Published: 24 November 2015 Correspondence to: B. Di Mauro (b.dimauro@campus.unimib.it)

Published by Copernicus Publications on behalf of the European Geosciences Union \& the American Geophysical Union.

\section{Power law distributions of wildfires across \\ Europe \\ B. Di Mauro et al.}

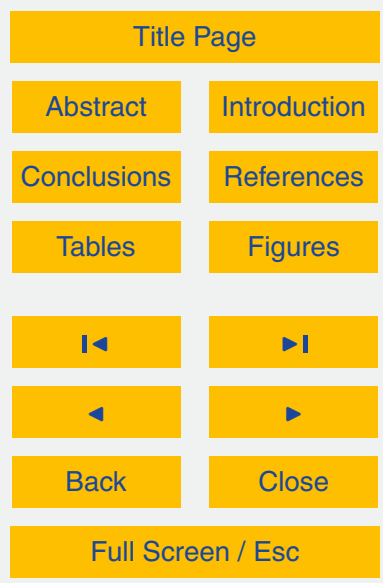

Printer-friendly Version

Interactive Discussion 


\section{Abstract}

Monthly wildfire burned area frequency is here modeled with a power law distribution and scaling exponent across different European biomes are estimated. Data sets, spanning from 2000 to 2009, comprehend the inventory of monthly burned areas from

5 the European Forest Fire Information System (EFFIS) and simulated monthly burned areas from a recent parameterization of a Land Surface Model (LSM), that is the Community Land Model (CLM). Power law exponents are estimated with a Maximum Likelihood Estimation (MLE) for different European biomes. The characteristic fire size (CFS), i.e. the area that most contributes to the total burned area, was also calcu10 lated both from EFFIS and CLM data set. We used the power law fitting and the CFS analysis to benchmark CLM model against the EFFIS observational wildfires data set available for Europe.

Results for the EFFIS data showed that power law fittings holds for 2-3 orders of magnitude in the Boreal and Continental ecoregions, whereas the distribution of the

15 Alpine, Atlantic are fitted only in the upper tail. Power law instead is not a suitable model for fitting CLM simulations.

CLM benchmarking analysis showed that the model strongly overestimates burned areas and fails in reproducing size-frequency distribution of observed EFFIS wildfires. This benchmarking analysis showed that some refinements in CLM structure (in particular regarding the anthropogenic influence) are needed for predicting future wildfires scenarios, since the low spatial resolution of the model and differences in relative frequency of small and large fires can affect the reliability of the predictions.

\section{Introduction}

Wildfire size frequency has been studied since fire data have been regularly collected and then analyzed to gain a mechanistic understanding of the underlying process and to develop predictive models of this complex natural phenomenon (Cumming,
NPGD

2, 1553-1586, 2015

Power law distributions of wildfires across Europe

B. Di Mauro et al.

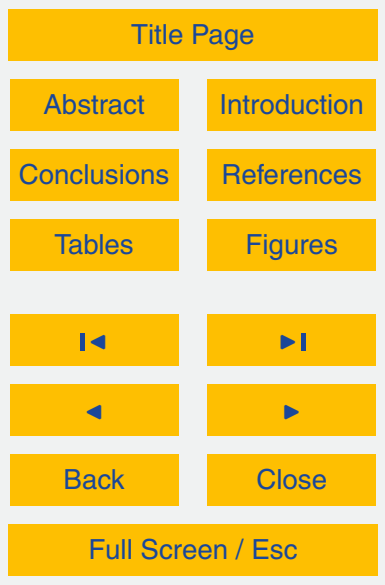

Printer-friendly Version

Interactive Discussion 
2001; McKenzie et al., 2011; Moritz et al., 2005; Zinck and Grimm, 2009). The spatiotemporal distribution of wildfires in a certain area can be used to characterize the fire regime. Although widely used, this term still lacks a clear and widely accepted definition (Krebs et al., 2010). Fire regimes are mainly a function of land cover (e.g. type 5 of fuel) and climate (temperature, precipitation, duration of the dry-wet season, etc.), but they also depend on socio-economic factors such as population density, agricultural practices and so on (Bowman et al., 2011; Pausas and Keeley, 2009). Recent climate change has been found to impact wildfire regimes and future increases in global temperature coupled with more frequent droughts is expected to increase fire activ10 ity (Flannigan et al., 2000), in particular in Mediterranean landscapes (Pausas, 2004). Despite some attempts based both on satellite (Chuvieco et al., 2008) and inventory data (Malamud et al., 2005a), to date there is no well-established/quantitative method for classifying fire regimes across different climates. A proper classification method is needed for the quantification of climate change impact on ecosystems and wildfire 15 scenarios (Migliavacca et al., 2013b; Yang et al., 2014).

Many difficulties are encountered in the modeling of wildfires because of the intrinsic complexity of this system, in which many environmental and social variables are involved in the ignition, propagation and suppression of fires. Some models were formulated to describe and predict wildfire spatial and temporal frequencies. According to Zinck and Grimm (2009) these models can be classified in two categories: the fire ecology approach and the statistical physics approach. The former class of models aims to reproduce environmental interactions between the physical status of vegetation and forcing agents that lead to wildfires (Peterson, 2002; Thonicke et al., 2008, 2010); the latter class of models analyzes emergent properties of wildfire using information from

fire catalogs and models them as cellular automata (Bak et al., 1987, 1990; Drossel and Schwabl, 1992).

Regarding the latter category of models, Bak et al. (1990) proposed an interpretation of the spatial distribution of wildfires involving the theory of Self-Organized Criticality (SOC). This theory was first formalized by Bak et al. (1987) for the explanation of

\section{NPGD}

2, 1553-1586, 2015
Power law distributions of wildfires across Europe

B. Di Mauro et al.

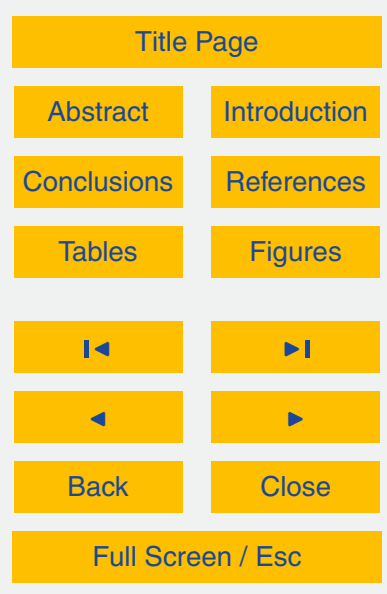

Printer-friendly Version

Interactive Discussion 
$1 / f$ noise, using the analogy of the "sand pile" model, and then widely applied in various fields (Hergarten and Krenn, 2011; Hergarten, 2002; Jørgensen et al., 1998; Malamud et al., 2005b; Newman, 1996; Pueyo, 2007; Turcotte and Malamud, 2004). In this framework, a simple dynamical system accumulates energy (and mass) for a certain 5 period of time and then energy is dissipated as a fractal (Bak et al., 1990) generating scale invariance in events magnitude (i.e. non-existence of a characteristic size of the process).

Emergent properties, such as the frequency-size scaling, can be revealed searching for power law distributions in empirical data (Burroughs and Tebbens, 2001; Clauset 10 et al., 2009; Deluca and Corral, 2013). Those distributions have been widely found in nature and these occurrences have often been linked to scale invariance and fractals. Power law theoretical background has been applied to different natural hazards (Turcotte and Malamud, 2004), such as earthquakes (Gutenberg and Richter, 1956), fracture systems (Bonnet et al., 2001), landslides (Frattini and Crosta, 2013; Guzzetti 15 et al., 2002; Malamud et al., 2004), rock and snow avalanches (Crosta et al., 2007; Birkeland, 2002), tropical cyclones (Corral et al., 2010) and wildfires (Malamud, 1998). For the latter, the scaling exponent of the power law has been estimated from different data sets in various geographic contexts (Corral et al., 2008; Fiorucci et al., 2008; Lin and Rinaldi, 2009; Malamud, 1998; Ricotta et al., 1999, 2001; Song et al., 2001, 2006). 20 Scaling exponents have been also interpreted as a proxy of fire regimes (Hantson et al., 2015) in North America (Malamud et al., 2005a; Millington et al., 2006) and in the Iberian Peninsula (Moreno et al., 2011). Nevertheless, the existence of a power law scaling in wildfires has been questioned by several authors (Reed and McKelvey, 2002; Benavent-Corai et al., 2007; McKenzie and Kennedy, 2012; Lehsten et al., 2014) and some uncertainties still remain about their frequency distribution. For example, Reed and McKelvey (2002) suggested that it is necessary to have a constant extinguishmentgrowth rate ratio (i.e. fire suppression and vegetation recovery are constant in space and time) to hold a power law at all sizes of burned areas. Since it is difficult for both extinguishment and growth to be spatially and temporally constant, a power law is

\section{NPGD}

2, 1553-1586, 2015
Power law distributions of wildfires across Europe

B. Di Mauro et al.

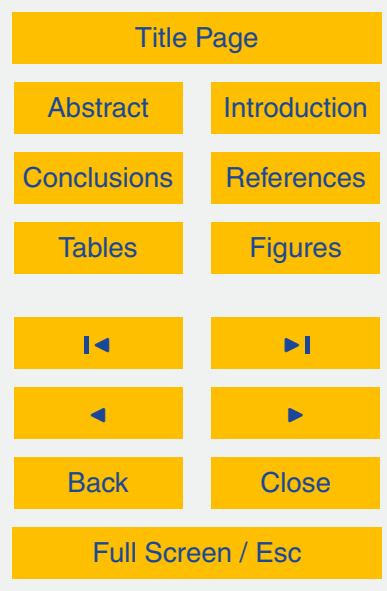

Printer-friendly Version

Interactive Discussion 
not expected to hold for the entire range of fire size. Recently, Lehsten et al. (2014) proposed an alternative statistics, the Characteristic Fire Size (CFS), to measure the fire size that contributes the most to the total burned area. CFS in the pan-Boreal area showed to explain the distribution of wildfires better than a power law distribution, using 5 two independent inventory datasets.

Regarding the fire models implemented in Land Surface Models (LSM), such as the Community Land Model (CLM), different comparison between observed and simulated data has been performed by many authors (Kloster et al., 2010; Migliavacca et al., 2013a; Thonicke et al., 2010). The ability of LSM to mimic realistic wildfires dynamic 10 has been questioned, and further comparison are needed to assess the reliability of LSM prediction for future global climate scenarios.

Recently Luo et al. (2012) proposed a framework methodology to benchmark LSM. Those benchmark analyses aim to: (i) target aspects of model performance to be evaluated, (ii) define a set of benchmarks as references to test model performance, (iii) com15 pare performance skills among models to identify model strengths and deficiencies, and (iv) propose model improvements. As scaling behavior of natural hazard represents an important insight in the complexity of this natural phenomenon, those scaling properties can be used as a benchmark for LSM. At date, only a work by Fletcher et al. (2014) incorporates power law scaling in dynamic global vegetation models (DGVMs), observing promising results for the Amazonian region.

In this paper, we benchmark a one version of the CLM model with power law scaling exponent and Characteristic Fire Size (CFS) calculations using a well-established observational data set of forest and non-forest wildfires (the European Forest Fire Information System, EFFIS) (Camia et al., 2014; Mclnerney et al., 2013). In particular, one criterion for model benchmarking is to evaluate how model structures are able to reproduce the relationships between a set of particular variables against a set of benchmarks, the latter derived from observed data. For this reason, we evaluated whether a LSM is able to mimic the probability of the distributions of wildfires in Europe that emerges from the analysis of a well-established observational dataset. The LSM here

\section{NPGD}

2, 1553-1586, 2015
Power law distributions of wildfires across Europe

B. Di Mauro et al.

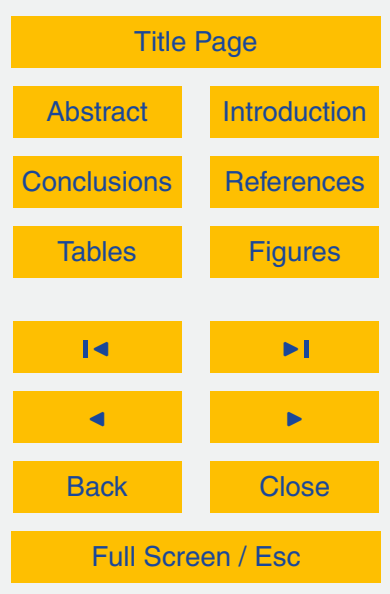

Printer-friendly Version

Interactive Discussion 
used is a recent parameterization of the CLM for its specific application in Europe (Migliavacca et al., 2013a, b). The comparison is performed because, although the model has been successfully applied to simulate the mean burned area and its relationship with environmental and climatic conditions (Kloster et al., 2010; Migliavacca 5 et al., 2013a), poor performances have been reported in the description of interannual variability and severe fire seasons (Migliavacca et al., 2013a). In particular, in Europe severe fire season characterized by large events (San-Miguel-Ayanz et al., 2013) are source of a great concern in the scientific community because of the direct link with climate extremes (e.g. 2003 and 2010 heat waves).

\section{Data sets and classifications}

\subsection{EFFIS inventory data}

The European Fire Database contains information on forest and grassland fires compiled by European Union Member States and by other European countries within the framework of the European Forest Fire Information System (EFFIS) (Camia et al., 15 2014).

EFFIS, the European Commission reference system for pan-European fire information, is a modular decision support system that monitors fires at a continental scale supporting fire management across Europe with the contributions of national forest fire services in the single countries (Mclnerney et al., 2013). In the EFFIS dataset, forest fires are defined as uncontrolled vegetation fires spreading wholly or in part on forest and/or other wooded land. Grasslands and shrublands are also included, while agricultural land is excluded from the fire statistics. We imposed a minimum fire size for data analysis equal to $1 \mathrm{ha}$, and they are often affected by undersampling. Fire size is the total burned area in hectares split into the main land cover categories affected.

Every year, contributing countries submit fire data derived from the collection of individual fire records, which are routinely compiled by local fire fighters after fires have

\section{NPGD}

2, 1553-1586, 2015

\section{Power law distributions of wildfires across Europe}

B. Di Mauro et al.

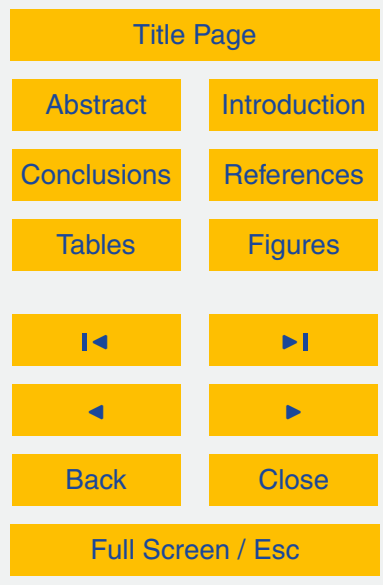

Printer-friendly Version

Interactive Discussion 
been extinguished. Data are checked, stored and managed by the Joint Research Centre (JRC) within the European Fire Database of EFFIS.

Among the available data, we used monthly totals of burned area from 2000 to 2009 in order to have a temporal resolution equal to the LSM. The EFFIS data were ag5 gregated at NUTS (Nomenclature of Territorial Units for Statistics, EUROSTAT, version 2006) level 3, which correspond to local administrative units of variable extent.

\subsection{CLM simulated data set}

The model simulations conducted in this study were performed with a modified version of CLM version 3.5 (e.g. Stöckli et al., 2008) extended with a carbon-nitrogen biogeochemical model (Randerson et al., 2009; Thornton et al., 2007, 2009). The prognostic treatment of fires is based on the algorithm developed by Kloster et al. (2010) and modified by Migliavacca et al. (2013b) for its application in Europe, where the model has been successfully applied to simulate fires for the present climate. Briefly, the model simulates burned area as a function of population density, soil moisture, biomass available to burn and wind-speed. The runs used in this study refer to the period 2000-2009, and were conducted at a spatial resolution of $0.9^{\circ} \times 1.2^{\circ}$ (Gaussian grid). CLM was forced by the ERA-Interim reanalysis obtained from the European Centre for MediumRange Weather Forecasts (ECMWF) (Dee et al., 2011). Specifically, six hourly data of air temperature, wind speed, specific humidity and atmospheric pressure, as well as 20 three hourly total of incoming shortwave radiation and precipitation were used. Population density data were obtained from the HYDE data set (Goldewijk, 2001) and regridded to match the model resolution applied in this study. The spin-up of the model was conducted according to Migliavacca et al. (2013b).

\subsection{Classification}

25 Both EFFIS and CLM data sets were classified using a simplified version of the climatic stratification proposed by Metzger et al. (2005), also known as the "Environmental

\section{NPGD}

2, 1553-1586, 2015
Power law distributions of wildfires across Europe

B. Di Mauro et al.

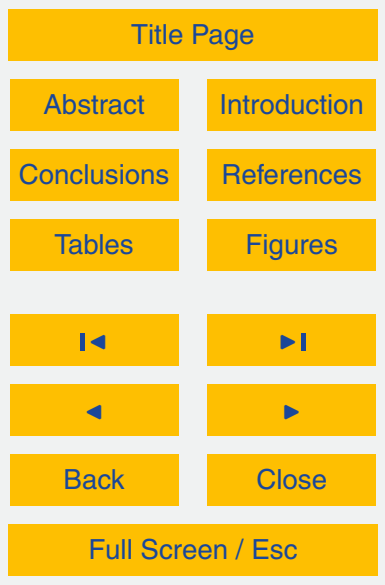

Printer-friendly Version

Interactive Discussion 
Stratification of Europe". This classification is based on a principal component analysis and a cluster analysis of available environmental variables. The original 13 environmental zones were merged into 5 classes (Fig. 1): Continental, Boreal, Atlantic, Alpine and Mediterranean, in order to resemble principal biomes in Europe and to avoid highly 5 fragmented classes that are incompatible with LSM resolution.

\section{Power law fitting}

Power law scaling exponents are expected to reveal emerging properties of complex systems. In this framework, different eco-climatic classes are expected to show different power law coefficients. Regarding wildfires: higher (absolute) values of the exponents could be interpreted as an indicator of a greater incidence of small monthly burned area with respect to the total burned area; conversely, lower exponents will reveal that the contribution of large extreme events to the total burned area is greater.

Power law exponents are here estimated using a Maximum Likelihood Estimation (MLE) (Clauset et al., 2009), in particular we used recent methodology based on MLE 15 applied to binned data (Virkar and Clauset, 2014).

Power law distributions are characteristic probability density distribution functions that can be expressed as:

$p(x) \propto x^{-\alpha}$

where $x$ is the measured or simulated quantity and $\alpha$ is a constant that assumes real values. Values of $\alpha$ are informative about the underlying process since they are closely related to scale invariance. In fact, when $\alpha<2$, the probability distribution of $x$ is characterized by all infinitive statistical moments, when $2 \leq \alpha<3$, the first moment (i.e. the mean) exists and all the other moments are infinite. Scale invariance occurrs when the probability $p(x)$ of an event of dimension $x$ is proportional to the probability $p(C x)$ of an event of dimension $C x$, in the formula:
NPGD

2, 1553-1586, 2015

Power law distributions of wildfires across Europe

B. Di Mauro et al.

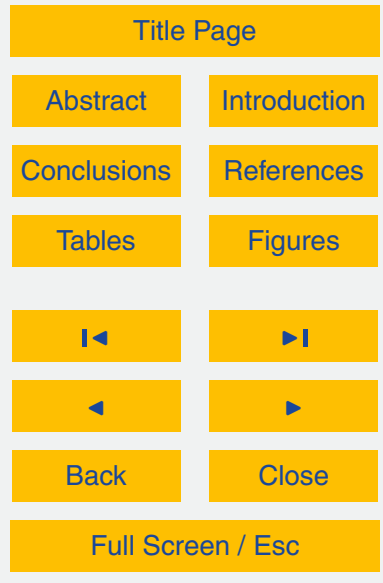

Printer-friendly Version

Interactive Discussion 
Consequently, in the dimension range of $x$ in which the power law holds, the characteristic size of the process cannot be calculated (non-existence of the mean) and the probability of an event of size $x$ occurring is proportional to that of an event of size $C x$. $5 \quad$ Clauset et al. (2009) proposed a unified method to fit power law distributions in empirical data, then modified by Virkar and Clauset (2014) for the application to binned data. Those methods have been largely applied by researchers interested in power law distribution and it can be summarized as follows. The estimated power law $\hat{\alpha}$ scaling exponent is calculated with a Maximum Likelihood Estimation (MLE):

${ }_{10} \hat{\alpha}=1+n\left[\sum_{i=1}^{n} \ln \frac{x_{i}}{x_{\min }}\right]^{-1}$

where $x_{i}, i=1,2, n$ are the observed values of $x$ such as $x_{i} \geq x_{\min }$. The goodness of fit is evaluated with a $p$ value from Kolmogorov-Smirnov statistics (Press et al., 2002) that measures the distance $D$ between the distribution of the empirical data and the hypothesized model (characterized by the estimated $\hat{\alpha}$ and $x_{\min }$ ). The $p$ value is defined

15 as the fraction of the synthetic distances that are larger than the empirical distance. If the $p$ value is larger than 0.1 , the fitting is statistically significant since the difference between the empirical data and the model can be attributed to statistical fluctuations alone.

Different probability distributions were tested against the power law. In particular, we here tested the lognormal, the exponential, the power law with exponential cut-off and the stretched exponential (Weibull) as possible competitors to the power law. Those functions are listed in Table 1.

The comparison is made by calculating the logarithm of the ratio of the two likelihoods (Loglikelihood Ratio, LR), since it provides a simple test statistic for discriminating power law from other distributions. LR assumes positive values if the first distribution (the power law) better fits the data with respect to another distribution, it is

\section{Power law distributions of wildfires across Europe}

B. Di Mauro et al.

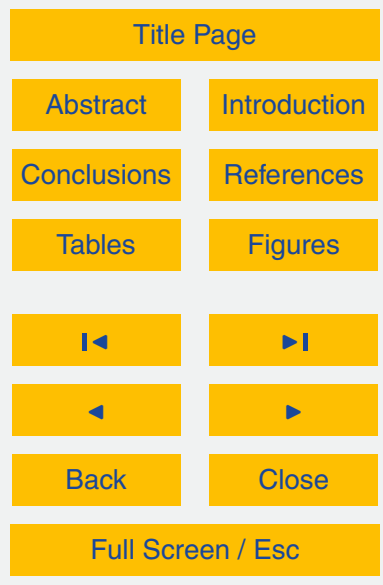

Printer-friendly Version

Interactive Discussion 
indistinguishable from zero in the event of a tie. The significance of this comparison is then assessed using the method proposed by Vuong (1989).

Data binning represents a delicate topic in power law research. Here we applied a standardized and objective binning scheme based on 20 bins distributed as a log5 arithm between the minimum and the maximum value of burned area for each class. This method is consistent with previous works that analyzed power law distributions in wildfires (Malamud et al., 2005a; Moreno et al., 2011; Ricotta et al., 1999).

It is important to underline that the method of fitting here applied aims to detect the power law above a minimum bin value. The method assumes that only a minimum 10 threshold exists and only the upper tail of the distribution is fitted by a power law or an alternative distribution.

The code for fitting power laws and testing alternative distribution was iteratively applied to each ecological class both for EFFIS and for CLM data sets. Then, the inverse cumulative distribution functions (CDF) were represented and results were compared.

154 Characteristic fire size

Recently, Lehsten et al. (2014) proposed a novel statistic to analyze wildfires size distribution called the Characteristic Fire Size (CFS). The authors claim that whether the CFS is normally distributed, this feature can be used as support for rejection the power law distribution of fire sizes. Here we calculate the CFS with the formula:

$\mathrm{CFS}_{i}=n_{f}(i)\langle m(i)\rangle$

where $n_{f}(i)$ is the burned areas in the $i$ th bin, and $\langle m(i)\rangle$ is the mean fire size in that bin. Representing the distribution of the CFS ${ }_{i}$ as a function of each bin, Lehsten et al. (2014) showed that this is approximated by a normal distribution for different panBoreal ecoregions. The maximum value of $\mathrm{CFS}_{i}$ can be used to represent the fire size that most contributes to the burned area, hereafter simply referred as CFS. In case of a power law distribution, CFS would show a linear pattern in a log-linear plot.

\section{NPGD}

2, 1553-1586, 2015

Power law distributions of wildfires across Europe

B. Di Mauro et al.

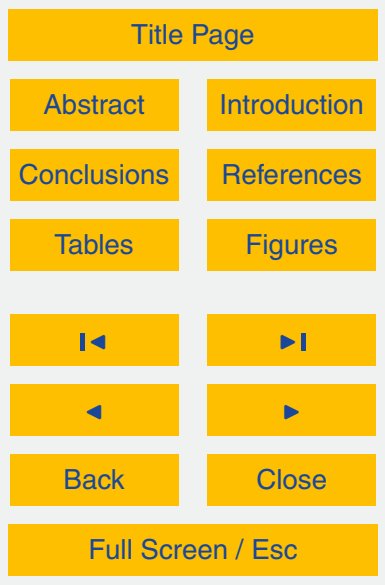

Printer-friendly Version

Interactive Discussion 
We calculated CFS for both CLM and EFFIS data, using the same binning scheme described in Sect. 3. Results are then are compared and CFS are spatially represented at European scale.

\section{Results}

5 First basic comparisons between EFFIS and CLM were made representing the two time series of sum of monthly burned area for the different ecoregions here analyzed (Fig. 2). As already reported using an administrative stratification (Migliavacca et al., 2013a), CLM strongly overestimates burned areas. We found this feature to hold true also for the climatic stratification applied here. In ecoregions characterized by a little fire 10 seasonality (i.e. Alpine, Atlantic and Continental), CLM badly reproduce EFFIS time series. For the Boreal domain, where fires spread mostly in the summer season and are almost absent during the winter and autumn, CLM qualitatively reproduces this trend observed in EFFIS data. Regarding the Mediterranean ecoregion, the strong seasonality of monthly burned area is reproduced by CLM. Further detailed and quantitative comparisons between EFFIS and CLM can be found in Migliavacca et al. (2013b).

The inverse cumulative distribution functions (CDF) of monthly burned areas are shown in Fig. 3. These results were obtained with the MLE method (Virkar and Clauset, 2014) and applied respectively to EFFIS and CLM data aggregated with the simplified Metzger classification (Metzger et al., 2005). Results for the EFFIS data set (red lines) showed statistical significance ( $\rho$ value of the Kolmogorov-Smirnov test $>0.1$ ) for all the classes. Values of the exponent $\alpha$ range from 1.84 to 3.63. Results from the statistical analysis are summarized in Table 1 . The minimum values for which the PL holds $\left(b_{\min }\right.$ in Table 1$)$ resulted higher for the Alpine, Atlantic and Mediterranean biomes, instead for the Boreal and Continental biomes we found low values of 40.8 and 29.7 ha, signifying that also small burned areas can be explained by the PL distribution.

The ranges of validity for the PL reach about three orders of magnitude for the Continental biome and about two orders for the Atlantic, Alpine and Boreal ecoregions. For

\section{NPGD}

2, 1553-1586, 2015

\section{Power law distributions of wildfires across Europe}

B. Di Mauro et al.

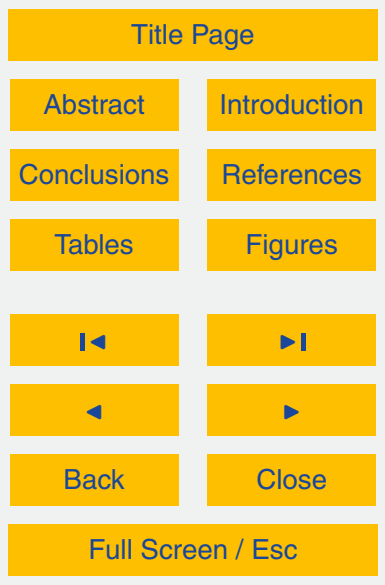

Printer-friendly Version

Interactive Discussion 
the Mediterranean biome, although statistically significant, only one order of magnitude of burned area is explained by the PL distribution. For the Boreal and Continental biomes we found a deviation from the power law fit in the tail of the distribution, often referred as "cut-off".

$5 \quad$ Regarding CLM data (green lines), power law fits are limited to the upper two bins of the whole distribution, signifying that the power law is not a suitable model for the description of those data and only the fires larger than $10^{5}$ behave like a power law. We accounted these fittings as spurious and non statistically sounding. The shape of the distributions in CLM data showed an overall accentuated curvature with respect to 10 the EFFIS for the Alpine, Atlantic and Mediterranean biomes. Instead, the Boreal and Continental biomes show a less accentuated curvature resembling more the observed EFFIS CDF.

In Table 3 are presented the Log-likelihood Ratio (LR) for the comparison of PL with other statistical distributions (summarized in Table 1). The positive sign of LR values 15 me means that, in the PL validity range, this distribution is favored against the others. The significance of the comparison was assessed by a statistical test (Vuong, 1989) that resulted significant for the majority of the comparisons. In some cases, the LR comparison was not statistically significant $(p>0.1)$, meaning that the sign of LR is not reliable and the test fails to favor one model distribution over the other. The last column of Table 3 shows the number of bins fitted by the power law distribution. We found that the power law holds against other distributions in many cases, but only for the Boreal and Continental biomes a high number of bins is fitted (respectively ten and twelve). For the Alpine and Atlantic biomes, five bins in the tail are fitted and for the Mediterranean biome, only three bins are fitted. We account this latter are spurious and not significant since the fitting regards only a few part of the total data.

Figure 4 shows the CFS plots for each ecoregion in Europe. Regarding EFFIS, the Alpine, Atlantic and Mediterranean biomes feature a similar behavior, where the CFS increases for small burned areas, reaches a maximum value and then decreases again for larger burned areas. For the Mediterranean ecoregion, data show a Gaus-

\section{NPGD}

2, 1553-1586, 2015
Power law distributions of wildfires across Europe

B. Di Mauro et al.

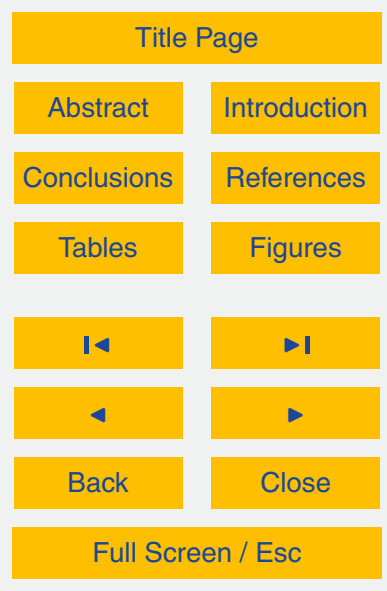

Printer-friendly Version

Interactive Discussion 
sian shape, since it is clearly discernible both an increasing and a decreasing trend, with a peak at 2069 ha $(\log C F S=3.31)$. The Boreal ecoregion show a bimodal distribution, the first peaks at 92.2 ha $(\log C F S=1.96)$ and the second one peaks at 729.7 ha (log CFS $=2.86$ ). For the Continental biome, we observed a continuous in5 creasing trend in the CFS, and no decreasing trend, except for two lower values in the uppermost part of the distribution. The marked overestimation of CLM results here in a separation between distributions. Furthermore, CLM data show a Gaussian-like shape, featuring a characteristic event size for all ecoregion, except for the Continental biome, that show an almost continuous increasing trend.

In Fig. 5, we show a spatial representation of power law exponents for the EFFIS data set at European scale. A latitudinal gradient is displayed in the map, where higher exponents are associated with lower latitudes and lower exponent are generally associated with higher latitudes. The map of power law exponent for the CLM is not showed here since those fitting resulted non statistically sound.

15 In Fig. 6, a map of CFS for the CLM simulated data is showed. Also in this case, a spatial pattern appears: higher CFS are displayed in the Mediterranean area and lower CFS in the Continental and Boreal areas. The map of CFS is here showed only for CLM since EFFIS data showed that not all the ecoregion allowed the estimation of a CFS.

The main objective of this work was to test whether a power law function approximates wildfires distribution across European biomes using two large data set (EFFIS and CLM). In particular, specific object was to use scaling coefficients to benchmark a land surface model (CLM) against a well-established observational data set (EFFIS). These objects address important questions regarding wildfire theoretical background, since whether fire size distribution follows or not a power law distribution in Europe represents a fundamental insight in the complexity of fire dynamics. We also remark that data

\section{NPGD}

2, 1553-1586, 2015

Power law distributions of

wildfires across

Europe

B. Di Mauro et al.

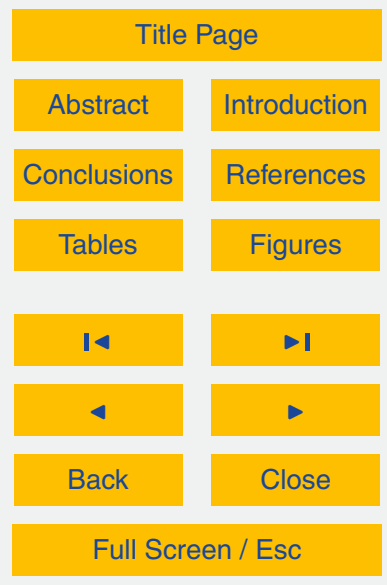

Printer-friendly Version

Interactive Discussion 
aggregation plays a fundamental role in power law scaling analysis (Fiorucci et al., 2008), since the more the single classes of data are coherent, the more emergent behavior are likely to appear (Cristelli et al., 2012).

In order to compare EFFIS and CLM dataset, we applied a temporal (monthly) and 5 spatial (ecoregions) aggregation of fires. This aggregation was necessary since CLM does not simulate single fires events but only temporal aggregated sums of burned area in each pixel, and for this specific dataset the aggregation is monthly. We also assumed that different European ecoregions features different fire dynamics and we aimed to characterize them with power laws, as previously applied by Malamud et al. (2005) in 10 North America.

Results from the EFFIS data set showed that wildfires distribution in the Boreal and Continental ecoregions feature a statistically sound power law for many orders of magnitude. The Alpine, Atlantic and Mediterranean ecoregion show a power law only in the upper tail of the distribution and only for a few orders of magnitude, we considered 15 those fit not significant for the purpose of the paper.

We interpret these results (Figs. 3 and 5) using the Self Organized Criticality (SOC) theoretical framework. In the Boreal and Continental biomes, wildfires feature a general lower incidence with respect the Mediterranean domain (De Groot et al., 2013). In the Boreal and Continental biomes, where mainly evergreen needle leaf and broad leaf forests are present, wildfires are a rare event that can spread also for large areas since the landscape is homogeneous and non-fragmented. Furthermore, those land covers are not very resilient to fire (Goetz et al., 2006; Lentile et al., 2006) and this could act like a feedback mechanism, where fire is prevented by the absence of fuel available to burn due to previous fire. The SOC framework can be applied here since 25 Boreal and Continental ecosystems accumulates (bio)mass (e.g. litter and deadwood) and energy through the seasonal cycles of vegetation by converting the constant input of solar radiation and carbon dioxide. Mass and energy are then dissipated by fire as a fractal, since small wildfires are naturally occurring in large number (Randerson et al., 2012), and when fire spreads it is difficultly suppressed before it can reach large exten-

\section{NPGD}

2, 1553-1586, 2015
Power law distributions of wildfires across Europe

B. Di Mauro et al.

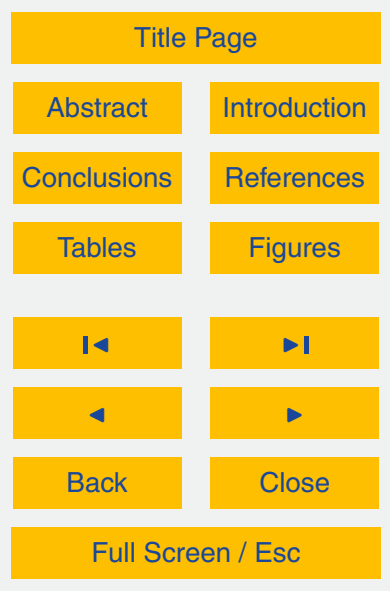

Printer-friendly Version

Interactive Discussion 
sion because of the small population density and little landscape fragmentation. In any case, very big fire events are prevented through fire suppression by fire-fighters, this may results in a deviation from the power law fit in the tail of the distribution (Fig. 3), often referred as a finite-size effect (Corral et al., 2010; Hergarten, 2002). These re5 sults support that Northern Europe ecosystem show a more natural fire regime, since the influence of humans is located mainly in the upper tail of the distribution, and fire ignition and spreading is more likely be dictated by climate and fuel availability.

CFS analysis on EFFIS data shows that Boreal and Continental biomes do not feature a characteristic size of monthly wildfires. In particular, the Boreal biome shows 10 a double peak in CFS plot (Fig. 4), this could mean that small and large fires follow a different behavior, which is instead masked in the cumulative distributions representation (Fig. 3). The Continental biome features no characteristic size, this can be used as a further support to the power law scaling.

Southern and Central Europe (SCE) biomes (i.e. Alpine, Atlantic and Mediterranean) 15 do not feature a statistically sound power law, and the CFS revealed that they show a Gaussian-like distribution featuring one characteristic dimension. SCE biomes are highly fragmented and wildfires are usually triggered and suppressed by human beings (Ganteaume et al., 2013). We claim that the high population density and landscape fragmentation play an important role in the lack of power law fit in SCE biomes. Wildfires are often triggered by arson or accidental causes (roughly in $90 \%$ of the total fires) that involve human being. Furthermore, active fire-fighting methods and efficient fire suppression, strongly limit the spreading of wildfires in different land covers. This results in a strong deviation from a "natural fire regime", where fire spreading is mainly dictated by climate variability and vegetation spatial distribution. Furthermore, these ecosystems are generally highly resilient to fire (Díaz-Delgado et al., 2003; Di Mauro et al., 2014) and repeated fire can happen in the same burn scar from one year to the subsequent, preventing the feedback mechanism described for the Boreal and Continental biomes. Also in these areas, large fires can occur; those events are possibly escaped from human suppression. For example, events like these can be triggered by

\section{NPGD}

2, 1553-1586, 2015
Power law distributions of wildfires across Europe

B. Di Mauro et al.

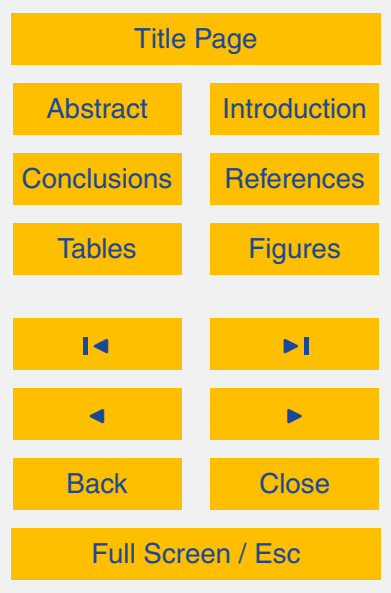

Printer-friendly Version

Interactive Discussion 
extreme heat waves (Barriopedro et al., 2011; Trigo et al., 2006) that create environmental conditions that promote large fires spreading. The CFS analysis showed that for the Mediterranean area a clear characteristic size can be calculated, instead for the Alpine and Atlantic biomes we found some noise in the upper tail of the distribution, 5 that can be related to the incidence of large fires, that is higher than expected in a lognormal distribution. In fact, for those two areas the power law analysis revealed that the scaling holds only in the upper tail with statistical significance, even if only a few bins are fitted by the power law.

Regarding the benchmark analysis of CLM, we used two methodologies: power law 10 fitting and the CFS analysis. From both results we found that in its current formulation, CLM badly reproduce the properties found in the EFFIS data set. In particular, the power law function is not a suitable description of wildfires distribution for all ecoregions in Europe. The fitting is limited to the upper two bins of the distribution, and we accounted it as not enough for a statistically sound fitting. The CFS analysis showed that, using CLM, in all the European ecoregion the mean values of burned area is well behaved, since a characteristic event size can be calculated from the peak of the Gaussian-like distributions represented in Fig. 4.

The model benchmarking strategy applied in this study showed that improvements are needed in using this model for prediction of the distribution of wildfires in Europe. This can be done by developing the model structure, for instance to reduce the overestimation in Central Europe and the lack of description of interannual variability (Migliavacca et al., 2013a). At the moment, fire suppression is parameterized just as a function of population density; we can suggest that, for example, including the scaling parameter in the model structure can help in limiting fire spreading and in representing in a more realistic way the incidence of wildfires in Europe. Another option is to use a model optimization based on multiple constrains, for instance by including the observed power laws by ecoregion to describe better the spatial variability of fire regimes. A pilot work by Fletcher et al. (2014) showed that including the scaling fac-

\section{NPGD}

2, 1553-1586, 2015
Power law distributions of wildfires across Europe

B. Di Mauro et al.

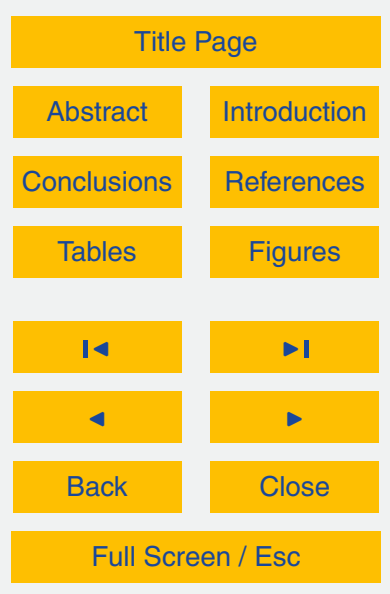

Printer-friendly Version

Interactive Discussion 
tor in a vegetation model increased the estimation accuracy of burned areas in the Amazonian region.

We also found that spatial representation of alpha exponents calculated from EFFIS data and CFS calculated from CLM clearly depicts differences in fire regime in Eu5 rope, as previously found in North America (Malamud et al., 2005a; Millington et al., 2006), since they display a latitudinal gradient related to the incidence of climate on fire regimes. In particular, lower scaling coefficient calculated from EFFIS are related to higher latitudes, instead higher CFS values calculated from CLM are related to lower latitudes.

10 Power law generating mechanisms play a fundamental role in the interpretation of results (Carlson and Doyle, 1999, 2002; Moritz et al., 2005); the fact that heavy-tailed distributions occur in complex systems implies that extreme events occur more frequently than they would in other distribution (Stumpf and Porter, 2012). This is an important issue in understanding the impact and relative frequency of large wildfires in 15 Europe (San-Miguel-Ayanz et al., 2013).

\section{Conclusions}

In this paper, we analyzed wildfire distribution across Europe using EFFIS and CLM data. Regarding EFFIS data, we found that cumulative distribution of Boreal and Continental biomes can be approximated by a power law function with statistical significance. Instead, the Mediterranean, Atlantic and Alpine biomes did not show significant fits. We interpreted these results as a result of a feedback mechanism between human management of wildfires and natural fire regime. We benchmarked CLM simulation with observed data, and we found that the model does not reproduce the scaling found in the Boreal and Continental biomes, and it strongly overestimates burned areas in all biomes. Possible constraints regarding the inclusion of scaling exponents in the model formulation are proposed in order to reduce the spreading of fire using EFFIS observed variability.

\section{NPGD}

2, 1553-1586, 2015
Power law distributions of wildfires across Europe

B. Di Mauro et al.

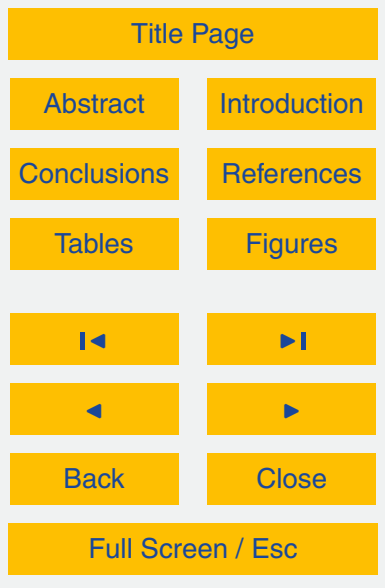

Printer-friendly Version

Interactive Discussion 
Based on theoretical considerations, we can also speculate that, if the power law properly describes wildfire distribution, it would be very unlikely observed at all orders of magnitude in inventory data or simulated monthly burned area that includes anthropogenic influence. Furthermore, since wildfire is a natural hazard with strong human 5 influences both in ignition and suppression, we conclude that a power law scaling behavior is likely observed only for natural environments, and deviation from the power law can be ascribed by the influence of human being on natural fire regimes.

Acknowledgements. We acknowledge the European Commission, Joint Research Centre (JRC), for providing the dataset extracted from the European Fire Database of EFFIS.

\section{References}

Bak, P., Tang, C., and Wiesenfeld, K.: Self-organized criticality: an explanation of the $1 / f$ noise, Phys. Rev. Lett., 59, 381-384, doi:10.1103/PhysRevLett.59.381, 1987.

Bak, P., Chen, K., and Tang, C.: A forest-fire model and some thoughts on turbulence, Phys. Lett. A, 147, 297-300, doi:10.1016/0375-9601(90)90451-S, 1990.

15 Barriopedro, D., Fischer, E. M., Luterbacher, J., Trigo, R. M., and García-Herrera, R.: The hot summer of 2010: redrawing the temperature record map of Europe, Science, 332, 220-224, doi:10.1126/science.1201224, 2011.

Benavent-Corai, J., Rojo, C., Suárez-Torres, J., and Velasco-García, L.: Scaling properties in forest fire sequences: the human role in the order of nature, Ecol. Model., 205, 336-342, doi:10.1016/j.ecolmodel.2007.02.028, 2007.

Birkeland, K. W.: Power-laws and snow avalanches, Geophys. Res. Lett., 29, 1554, doi:10.1029/2001GL014623, 2002.

Bonnet, E., Bour, O., Odling, N. E., Davy, P., Main, I., Cowie, P., and Berkowitz, B.: Scaling of fracture systems in geological media, Rev. Geophys., 39, 347-383, 25 doi:10.1029/1999RG000074, 2001.

Bowman, D. M. J. S., Balch, J., Artaxo, P., Bond, W. J., Cochrane, M. A., D’Antonio, C. M., Defries, R., Johnston, F. H., Keeley, J. E., Krawchuk, M. A., Kull, C. A., Mack, M., Moritz, M. A., Pyne, S., Roos, C. I., Scott, A. C., Sodhi, N. S., Swetnam, T. W., and Whittaker, R.: The hu-

\section{NPGD}

2, 1553-1586, 2015

\section{Power law distributions of wildfires across Europe}

B. Di Mauro et al.

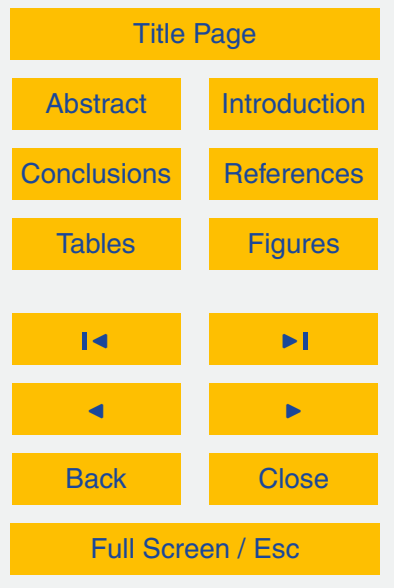

Printer-friendly Version

Interactive Discussion 
man dimension of fire regimes on Earth., J. Biogeogr., 38, 2223-2236, doi:10.1111/j.13652699.2011.02595.x, 2011.

Burroughs, S. M. and Tebbens, S. F.: Upper-truncated power laws in natural systems, Pure Appl. Geophys., 158, 741-757, 2001.

5 Camia, A., San-Miguel-Ayanz, J., and Durrant, T.: The European Fire Database: technical specifications and data submission, Publications Office of the European Union, European Union, Luxemburg, doi:10.2788/2175, 2014.

Carlson, J. M. and Doyle, J.: Highly optimized tolerance: a mechanism for power laws in designed systems, Phys. Rev. E, 60, 1412-1427, doi:10.1103/PhysRevE.60.1412, 1999.

10 Carlson, J. M. and Doyle, J.: Complexity and robustness, P. Natl. Acad. Sci. USA, 99, 25382545, doi:10.1073/pnas.012582499, 2002.

Chuvieco, E., Giglio, L., and Justice, C.: Global characterization of fire activity: toward defining fire regimes from Earth observation data, Global Change Biol., 14, 1488-1502, doi:10.1111/j.1365-2486.2008.01585.x, 2008.

15 Clauset, A., Shalizi, C. R., and Newman, M. E. J.: Power-law distributions in empirical data, SIAM Rev., 51, 661-703, doi:10.1137/070710111, 2009.

Corral, Á., Telesca, L., and Lasaponara, R.: Scaling and correlations in the dynamics of forestfire occurrence, Phys. Rev. E, 77, 016101, doi:10.1103/PhysRevE.77.016101, 2008.

Corral, Á., Ossó, A., and Llebot, J. E.: Scaling of tropical-cyclone dissipation, Nat. Phys., 6, 693-696, doi:10.1038/nphys1725, 2010.

Cristelli, M., Batty, M., and Pietronero, L.: There is more than a power law in Zipf, Sci. Rep., 2, 1-7, doi:10.1038/srep00812, 2012.

Crosta, G. B., Frattini, P., and Fusi, N.: Fragmentation in the Val Pola rock avalanche, Italian Alps, J. Geophys. Res., 112, F01006, doi:10.1029/2005JF000455, 2007.

Cumming, S. G.: A parametric model of the fire-size distribution, Can. J. Forest Res., 31, 12971303, doi:10.1139/x01-032, 2001.

Dee, D. P., Uppala, S. M., Simmons, A. J., Berrisford, P., Poli, P., Kobayashi, S., Andrae, U., Balmaseda, M. A., Balsamo, G., Bauer, P., Bechtold, P., Beljaars, A. C. M., van de Berg, L., Bidlot, J., Bormann, N., Delsol, C., Dragani, R., Fuentes, M., Geer, A. J., Haimberger, L., Healy, S. B., Hersbach, H., Hólm, E. V., Isaksen, L., Kållberg, P., Köhler, M., Matricardi, M., McNally, A. P., Monge-Sanz, B. M., Morcrette, J.-J., Park, B.-K., Peubey, C., de Rosnay, P., Tavolato, C., Thépaut, J.-N., and Vitart, F.: The ERA-Interim reanalysis: configuration and

\section{NPGD}

2, 1553-1586, 2015

\section{Power law distributions of wildfires across Europe}

B. Di Mauro et al.

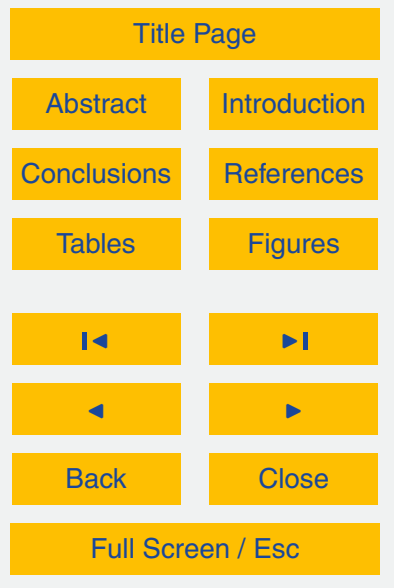

Printer-friendly Version

Interactive Discussion 
performance of the data assimilation system, Q. J. Roy. Meteorol. Soc., 137, 553-597, doi:10.1002/qj.828, 2011.

De Groot, W. J., Flannigan, M. D., and Cantin, A. S.: Climate change impacts on future boreal fire regimes, Forest Ecol. Manage., 294, 35-44, doi:10.1016/j.foreco.2012.09.027, 2013.

5 Deluca, A. and Corral, Á.: Fitting and goodness-of-fit test of non-truncated and truncated powerlaw distributions, Acta Geophys., 61, 1351-1394, doi:10.2478/s11600-013-0154-9, 2013.

Díaz-Delgado, R., Lloret, F., and Pons, X.: Influence of fire severity on plant regeneration by means of remote sensing imagery, Int. J. Remote Sens., 24, 1751-1763, doi:10.1080/01431160210144732, 2003.

10 Di Mauro, B., Fava, F., Busetto, L., Crosta, G. F., and Colombo, R.: Post-fire resilience in the Alpine region estimated from MODIS satellite multispectral data, Int. J. Appl. Earth Obs., 32, 163-172, doi:10.1016/j.jag.2014.04.010, 2014.

Drossel, B. and Schwabl, F.: Self-organized critical forest-fire model., Phys. Rev. Lett., 69, 1629-1632, 1992.

15 Fiorucci, P., Gaetani, F., and Minciardi, R.: Regional partitioning for wildfire regime characterization, J. Geophys. Res., 113, F02013, doi:10.1029/2007JF000771, 2008.

Flannigan, M., Stocks, B., and Wotton, B.: Climate change and forest fires, Sci. Total Environ., 262, 221-229, doi:10.1016/S0048-9697(00)00524-6, 2000.

Fletcher, I. N., Aragão, L. E. O. C., Lima, A., Shimabukuro, Y., and Friedlingstein, P.: Fractal properties of forest fires in Amazonia as a basis for modelling pan-tropical burnt area, Biogeosciences, 11, 1449-1459, doi:10.5194/bg-11-1449-2014, 2014.

Frattini, P. and Crosta, G. B.: The role of material properties and landscape morphology on landslide size distributions, Earth Planet. Sc. Lett., 361, 310-319, doi:10.1016/j.epsl.2012.10.029, 2013.

Ganteaume, A., Camia, A., Jappiot, M., San-Miguel-Ayanz, J., Long-Fournel, M., and Lampin, C.: A review of the main driving factors of forest fire ignition over Europe, Environ. Manage., 51, 651-62, doi:10.1007/s00267-012-9961-z, 2013.

Goetz, S. J., Fiske, G. J., and Bunn, A. G.: Using satellite time-series data sets to analyze fire disturbance and forest recovery across Canada, Remote Sens. Environ., 101, 352-365, doi:10.1016/j.rse.2006.01.011, 2006.

Goldewijk, K. K.: Estimating global land use change over the past 300 years: the HYDE Database, Global Biogeochem. Cy., 15, 417-433, doi:10.1029/1999GB001232, 2001.

\section{NPGD}

2, 1553-1586, 2015

\section{Power law distributions of wildfires across Europe}

B. Di Mauro et al.

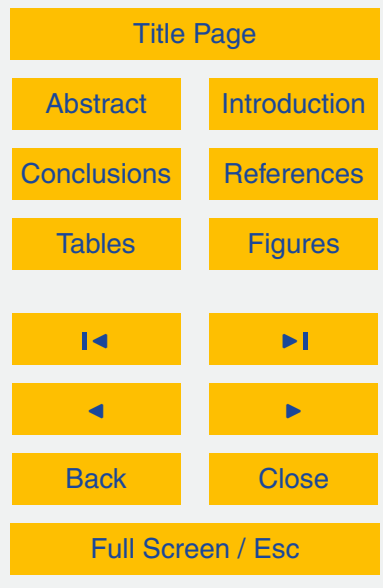

Printer-friendly Version

Interactive Discussion 
Gutenberg, B. and Richter, C. F.: Magnitude and energy of earthquakes, Ann. Geophys., 9, 1-15, doi:10.4401/ag-5590, 1956.

Guzzetti, F., Malamud, B. D., Turcotte, D. L., and Reichenbach, P.: Power-law correlations of landslide areas in central Italy, Earth Planet. Sc. Lett., 195, 169-183, doi:10.1016/S0012821X(01)00589-1, 2002.

Hantson, S., Pueyo, S., and Chuvieco, E.: Global fire size distribution is driven by human impact and climate, Global Ecol. Biogeogr., 24, 77-86, doi:10.1111/geb.12246, 2015.

Hergarten, S.: Self-Organized Criticality in Earth Systems, Springer, Berlin, Heidelberg, 2002.

Hergarten, S. and Krenn, R.: A semi-phenomenological approach to explain the event-size distribution of the Drossel-Schwabl forest-fire model, Nonlin. Processes Geophys., 18, 381388, doi:10.5194/npg-18-381-2011, 2011.

Jørgensen, S. E., Mejer, H., and Nielsen, S. N.: Ecosystem as self-organizing critical systems, Ecol. Model., 111, 261-268, doi:10.1016/S0304-3800(98)00104-5, 1998.

Kloster, S., Mahowald, N. M., Randerson, J. T., Thornton, P. E., Hoffman, F. M., Levis, S., 15 Lawrence, P. J., Feddema, J. J., Oleson, K. W., and Lawrence, D. M.: Fire dynamics during the 20th century simulated by the Community Land Model, Biogeosciences, 7, 1877-1902, doi:10.5194/bg-7-1877-2010, 2010.

Krebs, P., Pezzatti, G. B., Mazzoleni, S., Talbot, L. M., and Conedera, M.: Fire regime: history and definition of a key concept in disturbance ecology, Theory Biosci., 129, 53-69, doi:10.1007/s12064-010-0082-z, 2010.

Lehsten, V., de Groot, W. J., Flannigan, M., George, C., Harmand, P., and Balzter, H.: Wildfires in boreal ecoregions: evaluating the power law assumption and intra-annual and interannual variations, J. Geophys. Res.-Biogeo., 119, 14-23, doi:10.1002/2012JG002252, 2014.

Lentile, L. B., Holden, Z. A., Smith, A. M. S., Falkowski, M. J., Hudak, A. T., Morgan, P., Lewis, S. A., Gessler, P. E., and Benson, N. C.: Remote sensing techniques to assess active fire characteristics and post-fire effects, Int. J. Wildland Fire, 15, 319-345, doi:10.1071/WF05097, 2006.

Lin, J. and Rinaldi, S.: A derivation of the statistical characteristics of forest fires, Ecol. Model., 220, 898-903, doi:10.1016/j.ecolmodel.2009.01.011, 2009.

30 Luo, Y. Q., Randerson, J. T., Abramowitz, G., Bacour, C., Blyth, E., Carvalhais, N., Ciais, P., Dalmonech, D., Fisher, J. B., Fisher, R., Friedlingstein, P., Hibbard, K., Hoffman, F., Huntzinger, D., Jones, C. D., Koven, C., Lawrence, D., Li, D. J., Mahecha, M., Niu, S. L., Norby, R., Piao, S. L., Qi, X., Peylin, P., Prentice, I. C., Riley, W., Reichstein, M., Schwalm, C.,

\section{NPGD}

2, 1553-1586, 2015

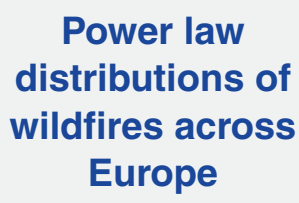

B. Di Mauro et al.

Title Page

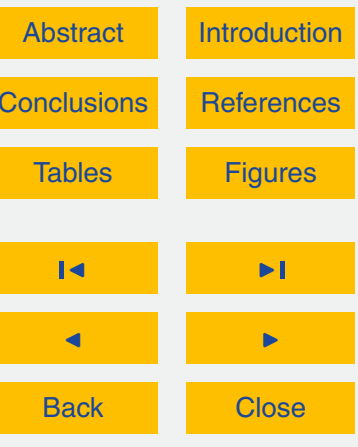

Full Screen / Esc

Printer-friendly Version

Interactive Discussion 
Wang, Y. P., Xia, J. Y., Zaehle, S., and Zhou, X. H.: A framework for benchmarking land models, Biogeosciences, 9, 3857-3874, doi:10.5194/bg-9-3857-2012, 2012.

Malamud, B. D.: Forest fires: an example of self-organized critical behavior, Science, 281, 1840-1842, doi:10.1126/science.281.5384.1840, 1998.

5 Malamud, B. D., Millington, J. D. A., and Perry, G. L. W.: Characterizing wildfire regimes in the United States, P. Natl. Acad. Sci. USA, 102, 4694-4699, doi:10.1073/pnas.0500880102, 2005a.

Malamud, B. D., Morein, G., and Turcotte, D. L.: Log-periodic behavior in a forest-fire model, Nonlin. Processes Geophys., 12, 575-585, doi:10.5194/npg-12-575-2005, 2005b.

10 Malamud, B. D., Turcotte, D. L., Guzzetti, F., and Reichenbach, P.: Landslide inventories and their statistical properties, Earth Surf. Proc. Land., 29, 687-711, doi:10.1002/esp.1064, 2004.

Mclnerney, D., San-Miguel-Ayanz, J., Corti, P., Whitmore, C., Giovando, C., and Camia, A.: Design and function of the European forest fire information system, Photogramm. Eng. Rem. S., 79, 965-973, doi:10.14358/PERS.79.10.965, 2013.

McKenzie, D. and Kennedy, M. C.: Power laws reveal phase transitions in landscape controls of fire regimes, Nat. Commun., 3, 1-6, doi:10.1038/ncomms1731, 2012.

McKenzie, D., Miller, C., and Falk, D. A. (Eds.): The Landscape Ecology of Fire, Springer, Dordrecht, the Netherlands, 2011.

20 Metzger, M. J., Bunce, R. G. H., Jongman, R. H. G., Mücher, C. A., and Watkins, J. W.: A climatic stratification of the environment of Europe, Global Ecol. Biogeogr., 14, 549-563, doi:10.1111/j.1466-822X.2005.00190.x, 2005.

Migliavacca, M., Dosio, A., Kloster, S., Ward, D. S., Camia, A., Houborg, R., Houston Durrant, T., Khabarov, N., Krasovskii, A. A., San Miguel-Ayanz, J., and Cescatti, A.: Modeling burned area in Europe with the community land model, J. Geophys. Res.-Biogeo., 118, 265-279, doi:10.1002/jgrg.20026, 2013a.

Migliavacca, M., Dosio, A., Camia, A., Hobourg, R., Houston-Durrant, T., Kaiser, J. W., Khabarov, N., Krasovskii, A. A., Marcolla, B., San Miguel-Ayanz, J., Ward, D. S., and Cescatti, A.: Modeling biomass burning and related carbon emissions during the 21 st century

\section{NPGD}

2, 1553-1586, 2015

\section{Power law distributions of wildfires across Europe}

B. Di Mauro et al.

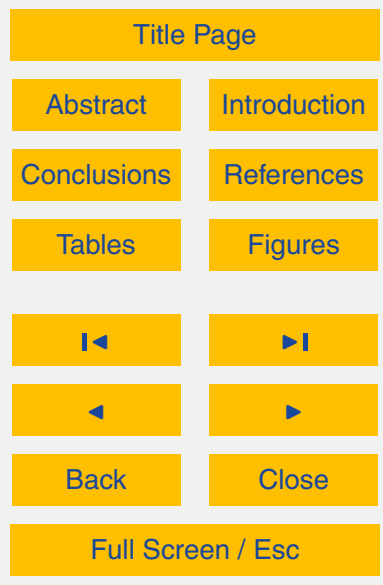

Printer-friendly Version

Interactive Discussion mechanisms: quantifying wildfire regimes, Geol. Soc. Spec. Publ., 261, 155-167, doi:10.1144/GSL.SP.2006.261.01.12, 2006. 
Moreno, M. V., Malamud, B. D., and Chuvieco, E. A.: Wildfire frequency-area statistics in Spain, Procedia Environ. Sci., 7, 182-187, doi:10.1016/j.proenv.2011.07.032, 2011.

Moritz, M. A., Morais, M. E., Summerell, L. A., Carlson, J. M., and Doyle, J.: Wildfires, complexity, and highly optimized tolerance, P. Natl. Acad. Sci. USA, 102, 17912-17917, 2005.

5 Newman, M.: Self-organized criticality, evolution and the fossil extinction record, Proc. R. Soc., 3801, 1-20, available at: http://rspb.royalsocietypublishing.org/content/263/1376/1605.short (last access: 7 May 2014), 1996.

Pausas, J. G.: Changes in fire and climate in the Eastern Iberian Peninsula (Mediterranean Basin), Climatic Change, 63, 337-350, doi:10.1023/B:CLIM.0000018508.94901.9c, 2004.

10 Pausas, J. G. and Keeley, J. E.: A burning story: the role of fire in the history of life, Bioscience, 59, 593-601, doi:10.1525/bio.2009.59.7.10, 2009.

Peterson, G. D.: Contagious disturbance, ecological memory, and the emergence of landscape pattern, Ecosystems, 5, 329-338, doi:10.1007/s10021-001-0077-1, 2002.

Press, W. H., Teukolsky, S. A., Vetterling, W. T., and Flannery, B. P.: Numerical Recipes in C, the 15 Art of Scientific Computing, Cambridge University Press, Cambridge, UK, New York, USA, 2002.

Pueyo, S.: Self-organised criticality and the response of wildland fires to climate change, Climatic Change, 82, 131-161, doi:10.1007/s10584-006-9134-2, 2007.

Randerson, J. T., Chen, Y., van der Werf, G. R., Rogers, B. M., and Morton, D. C.: Global burned area and biomass burning emissions from small fires, J. Geophys. Res., 117, G04012, doi:10.1029/2012JG002128, 2012.

Randerson, J. T., Hoffman, F. M., Thornton, P. E., Mahowald, N. M., Lindsay, K., Lee, Y. H., Nevison, C. D., Doney, S. C., Bonan, G., Stöckli, R., Covey, C., Running, S. W., and Fung, I. Y.: Systematic assessment of terrestrial biogeochemistry in coupled climate-carbon models, Global Change Biol., 15, 2462-2484, doi:10.1111/j.1365-2486.2009.01912.x, 2009.

Reed, W. J. and McKelvey, K. S.: Power-law behaviour and parametric models for the sizedistribution of forest fires, Ecol. Model., 150, 239-254, doi:10.1016/S0304-3800(01)00483-5, 2002.

Ricotta, C., Avena, G., and Marchetti, M.: The flaming sandpile: self-organized criticality and wildfires, Ecol. Model., 119, 73-77, doi:10.1016/S0304-3800(99)00057-5, 1999.

Ricotta, C., Arianoutsou, M., Díaz-Delgado, R., Duguy, B., Lloret, F., Maroudi, E., Mazzoleni, S., Manuel Moreno, J., Rambal, S., Vallejo, R., and Vázquez, A.: Self-organized criticality of wild-

NPGD

2, 1553-1586, 2015

\section{Power law distributions of wildfires across Europe}

B. Di Mauro et al.

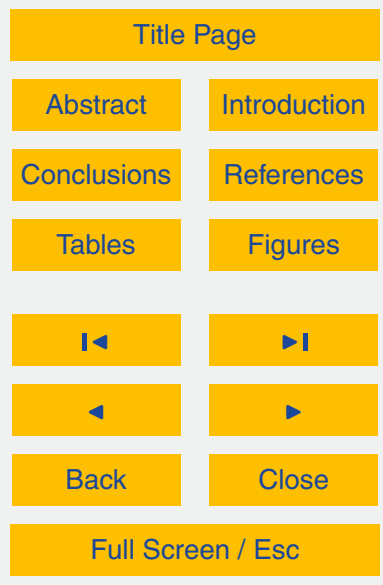

Printer-friendly Version

Interactive Discussion 
fires ecologically revisited, Ecol. Model., 141, 307-311, doi:10.1016/S0304-3800(01)00272$1,2001$.

San-Miguel-Ayanz, J., Moreno, J. M., and Camia, A.: Analysis of large fires in European Mediterranean landscapes: lessons learned and perspectives, Forest Ecol. Manage., 294, 11-22, doi:10.1016/j.foreco.2012.10.050, 2013.

Song, W., Weicheng, F., Binghong, W., and Jianjun, Z.: Self-organized criticality of forest fire in China, Ecol. Model., 145, 61-68, doi:10.1016/S0304-3800(01)00383-0, 2001.

Song, W., Wang, J., Satoh, K., and Fan, W.: Three types of power-law distribution of forest fires in Japan, Ecol. Model., 196, 527-532, doi:10.1016/j.ecolmodel.2006.02.033, 2006.

10 Stöckli, R., Lawrence, D. M., Niu, G.-Y., Oleson, K. W., Thornton, P. E., Yang, Z.-L., Bonan, G. B., Denning, A. S., and Running, S. W.: Use of FLUXNET in the community land model development, J. Geophys. Res., 113, G01025, doi:10.1029/2007JG000562, 2008.

Stumpf, M. P. H. and Porter, M. A.: Mathematics. Critical truths about power laws, Science, 335, 665-666, doi:10.1126/science.1216142, 2012.

15 Thonicke, K., Venevsky, S., Sitch, S., and Cramer, W.: The role of fire disturbance for global vegetation dynamics: coupling fire into a Dynamic global vegetation model, Global Ecol. Biogeogr., 10, 661-677, doi:10.1046/j.1466-822X.2001.00175.x, 2008.

Thonicke, K., Spessa, A., Prentice, I. C., Harrison, S. P., Dong, L., and Carmona-Moreno, C.: The influence of vegetation, fire spread and fire behaviour on biomass burning and trace gas emissions: results from a process-based model, Biogeosciences, 7, 1991-2011, doi:10.5194/bg-7-1991-2010, 2010.

Thornton, P. E., Lamarque, J.-F., Rosenbloom, N. A., and Mahowald, N. M.: Influence of carbonnitrogen cycle coupling on land model response to $\mathrm{CO}_{2}$ fertilization and climate variability, Global Biogeochem. Cy., 21, GB4018, doi:10.1029/2006GB002868, 2007.

Thornton, P. E., Doney, S. C., Lindsay, K., Moore, J. K., Mahowald, N., Randerson, J. T., Fung, I., Lamarque, J.-F., Feddema, J. J., and Lee, Y.-H.: Carbon-nitrogen interactions regulate climate-carbon cycle feedbacks: results from an atmosphere-ocean general circulation model, Biogeosciences, 6, 2099-2120, doi:10.5194/bg-6-2099-2009, 2009.

Trigo, R. M., Pereira, J. M. C., Pereira, M. G., Mota, B., Calado, T. J., Dacamara, C. C., and 30 Santo, F. E.: Atmospheric conditions associated with the exceptional fire season of 2003 in Portugal, Int. J. Climatol., 26, 1741-1757, doi:10.1002/joc.1333, 2006.

\section{NPGD}

2, 1553-1586, 2015

\section{Power law distributions of wildfires across Europe}

B. Di Mauro et al.

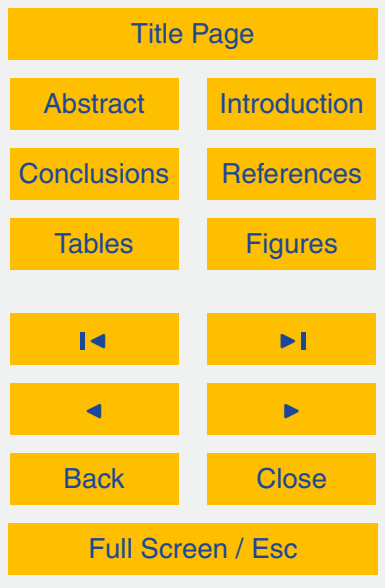

Printer-friendly Version

Interactive Discussion 
Turcotte, D. L. and Malamud, B. D.: Landslides, forest fires, and earthquakes: examples of self-organized critical behavior, Physica A, 340, 580-589, doi:10.1016/j.physa.2004.05.009, 2004.

Virkar, Y. and Clauset, A.: Power-law distributions in binned empirical data, Ann. Appl. 5 Stat., 8, 89-119, available at: http://projecteuclid.org/euclid.aoas/1396966280, last access: 20 June 2014.

Vuong, Q. H.: Likelihood ratio tests for model selection and non-nested hypotheses, Econometrica, 57, 307-333, doi:10.2307/1912557, 1989.

Yang, J., Tian, H., Tao, B., Ren, W., Kush, J., Liu, Y., and Wang, Y.: Spatial and temporal patterns of global burned area in response to anthropogenic and environmental factors: reconstructing global fire history for the 20th and early 21 st centuries, J. Geophys. Res.-Biogeo., 119, 249-263, doi:10.1002/2013JG002532, 2014.

Zinck, R. D. and Grimm, V.: Unifying wildfire models from ecology and statistical physics, Am. Nat., 174, E170-E185, doi:10.1086/605959, 2009.

\section{NPGD}

2, 1553-1586, 2015

\section{Power law distributions of wildfires across Europe}

B. Di Mauro et al.

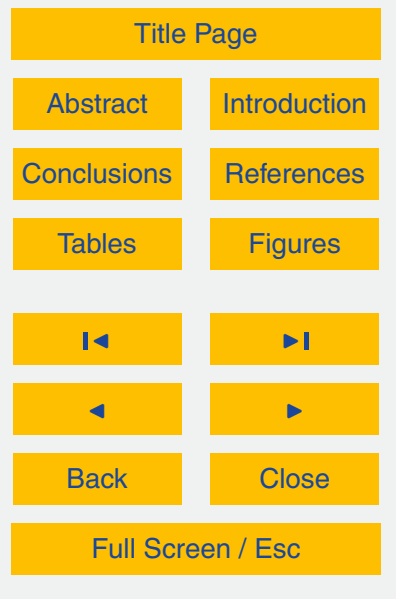

Printer-friendly Version

Interactive Discussion 
Table 1. Alternative probability distributions tested against the power law.

\begin{tabular}{ll}
\hline Function name & Functional form $f(x)$ \\
\hline Power law with cutoff & $x^{-\alpha} e^{-\lambda x}$ \\
Exponential & $e^{-\lambda x}$ \\
Stretched exponential & $x^{\beta-1} e^{-\lambda x \beta}$ \\
Lognormal & $\frac{1}{x} e^{\left[-\frac{(\ln x-\mu)^{2}}{2 \sigma^{2}}\right]}$ \\
\hline
\end{tabular}

NPGD

2, 1553-1586, 2015

\section{Power law distributions of wildfires across Europe}

B. Di Mauro et al.

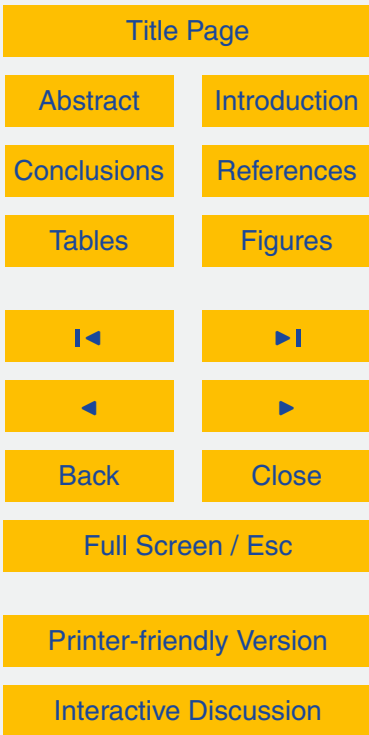


Table 2. Summary of power law fits for the EFFIS data set. Significant Kolmogorov-Smirnov (KS) $p$ values are marked in bold.

\begin{tabular}{lcrc}
\hline Ecoregion & Alpha & $b_{\min }(\mathrm{ha})$ & $\mathrm{KS} p$ value \\
\hline Alpine & 2.75 & 449.4 & $\mathbf{0 . 7 9}$ \\
Atlantic & 2.55 & 2905.1 & $\mathbf{0 . 6 2}$ \\
Boreal & 2.16 & 40.8 & $\mathbf{0 . 1 5}$ \\
Continental & 1.84 & 29.7 & $\mathbf{0 . 4 4}$ \\
Mediterranean & 3.63 & 6158.5 & $\mathbf{0 . 7 2}$ \\
\hline
\end{tabular}

NPGD

2, 1553-1586, 2015

\section{Power law} distributions of wildfires across Europe

B. Di Mauro et al.

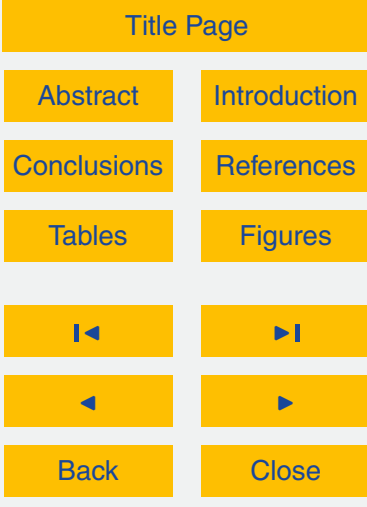

Full Screen / Esc

Printer-friendly Version

Interactive Discussion 
Table 3. Logarithms of the likelihood ratio (LR) between a power law distribution and four alternative distribution for the EFFIS data set. Positive values of the ratio means that the power law is favored over the alternatives. Significances are expressed for $p<0.001\left({ }^{a}\right), p<0.01\left(^{b}\right)$, $p<0.05\left(^{\circ}\right), p>0.1$ (non-significant, ns). Last column contains the number of fitted bins in the tail. Bold numbers are the statistically significant ones.

\begin{tabular}{lllllr}
\hline Ecoregion & Lognormal & Exponential & $\begin{array}{l}\text { Power law } \\
\text { with cut off }\end{array}$ & $\begin{array}{l}\text { Stretched } \\
\text { exponential }\end{array}$ & n. bins \\
\hline Alpine & $\mathbf{4 . 8}^{\mathrm{a}}$ & $\mathbf{5 . 0 3}^{\mathrm{a}}$ & $\mathbf{1 . 7 3}^{\mathrm{c}}$ & $\mathbf{5 . 3 9 ^ { \mathrm { a } }}$ & 5 \\
Atlantic & $\mathbf{4 . 4}^{\mathrm{a}}$ & $\mathbf{3 . 6 5}^{\mathrm{a}}$ & $0.82 \mathrm{~ns}$ & $\mathbf{3 . 8}^{\mathrm{a}}$ & 5 \\
Boreal & $\mathbf{2 . 8}^{\mathrm{a}}$ & $\mathbf{5 . 8 6}^{\mathrm{a}}$ & $1.52 \mathrm{~ns}$ & $\mathbf{1 . 9 9}^{\mathrm{b}}$ & 10 \\
Continental & $0.37 \mathrm{~ns}$ & $\mathbf{9 . 9 3}^{\mathrm{a}}$ & $\mathbf{3 . 3 3 ^ { \mathrm { a } }}$ & $0.24 \mathrm{~ns}$ & 12 \\
Mediterranean & $\mathbf{4 . 6 1}^{\mathrm{a}}$ & $\mathbf{2 . 7 8}^{\mathrm{a}}$ & $0.88 \mathrm{~ns}$ & $\mathbf{3 . 5 8}^{\mathrm{a}}$ & 3 \\
\hline
\end{tabular}

\section{NPGD}

2, 1553-1586, 2015

\section{Power law distributions of wildfires across Europe}

B. Di Mauro et al.

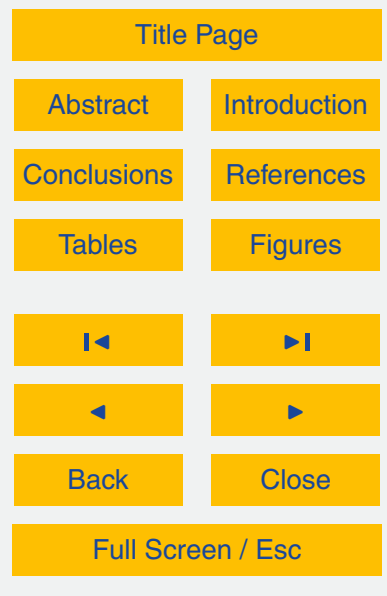

Printer-friendly Version

Interactive Discussion 


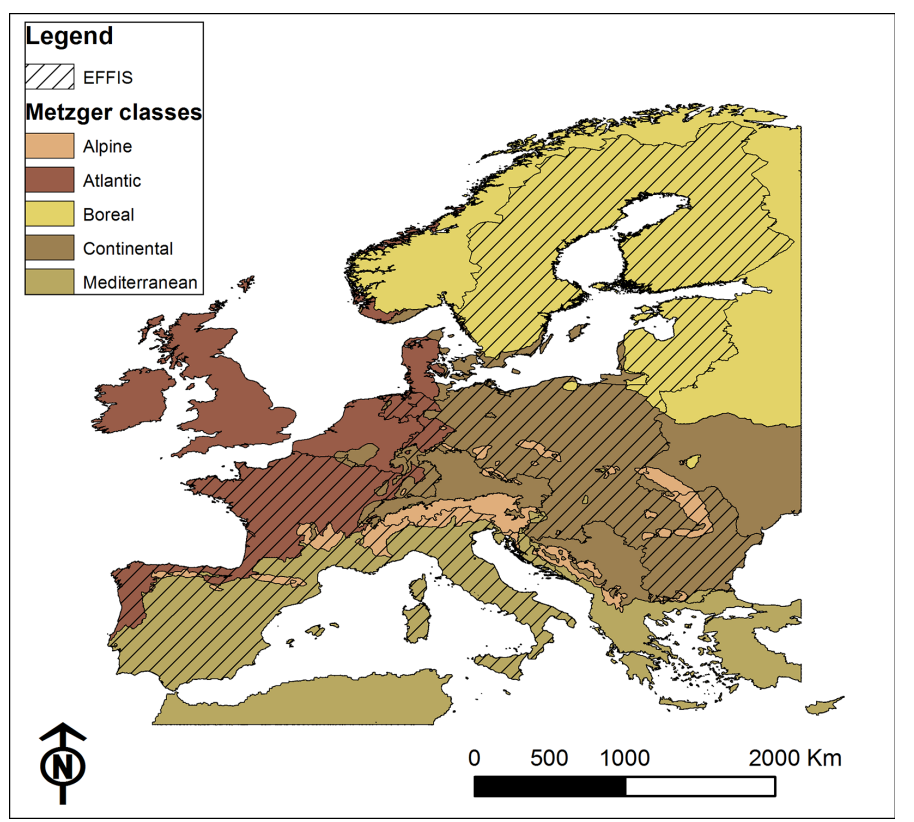

\section{NPGD}

2, 1553-1586, 2015

\section{Power law distributions of wildfires across Europe}

B. Di Mauro et al.

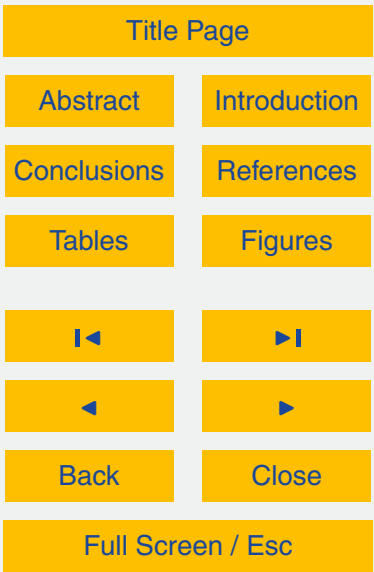

Figure 1. Climatic classification of European environment (Metzger et al., 2005). The 5 class stratification used here include Continental, Boreal, Atlantic, Alpine and Mediterranean. Shaded areas represent the available EFFIS data set in the considered period (2000-2009). 

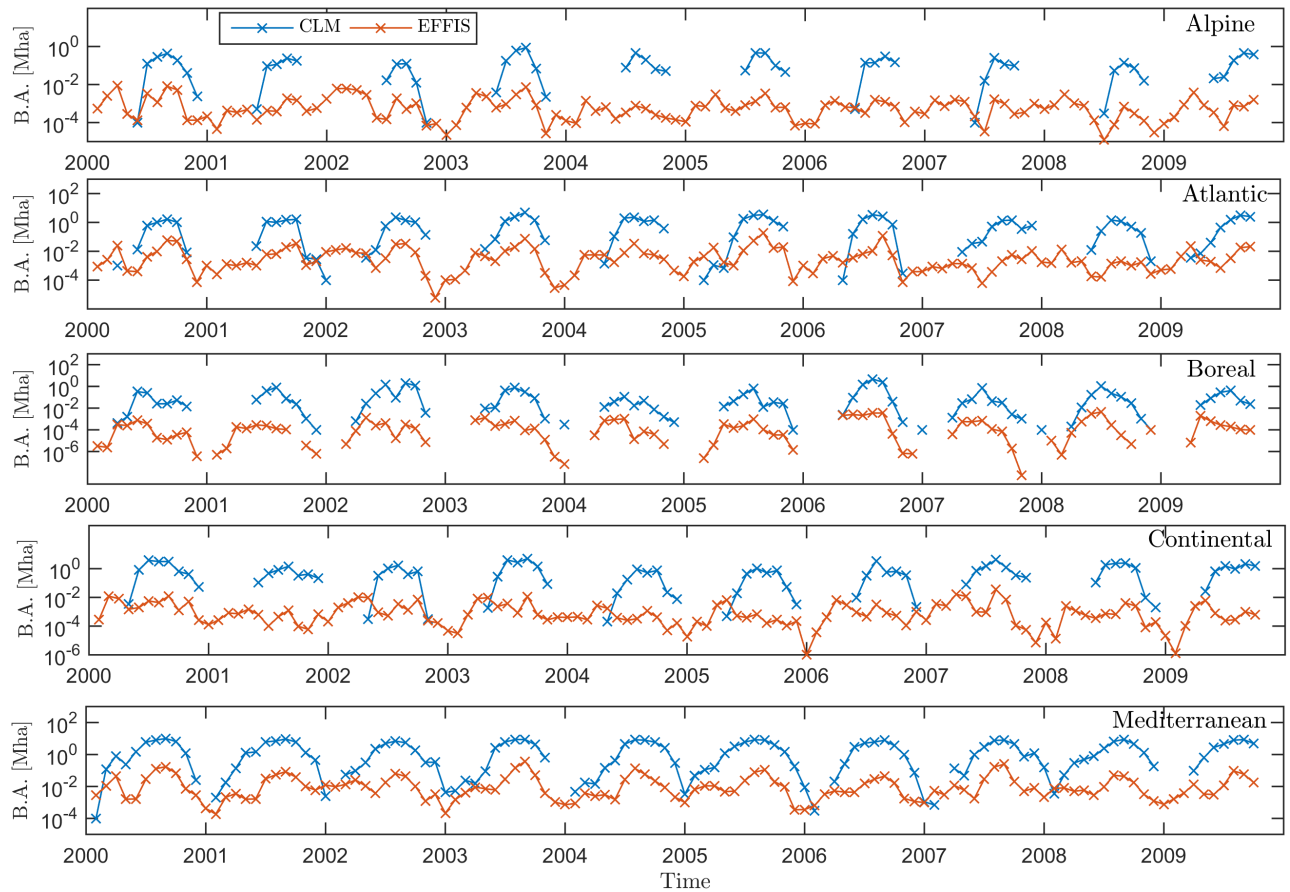

Figure 2. Monthly burned area time series for different ecoregions across Europe for the EFFIS (orange line) and CLM (blue line) data set. Note that ordinates are represented in a logarithmic scale.

NPGD

2, 1553-1586, 2015

\section{Power law distributions of wildfires across Europe}

B. Di Mauro et al.

\section{Title Page}

\begin{tabular}{c|c|}
\hline Abstract & Introduction \\
\hline Conclusions & References \\
\hline Tables & Figures \\
\hline I4 & \\
\hline 4 & \\
\hline Back & Close \\
\hline
\end{tabular}

Full Screen / Esc

Printer-friendly Version

Interactive Discussion 

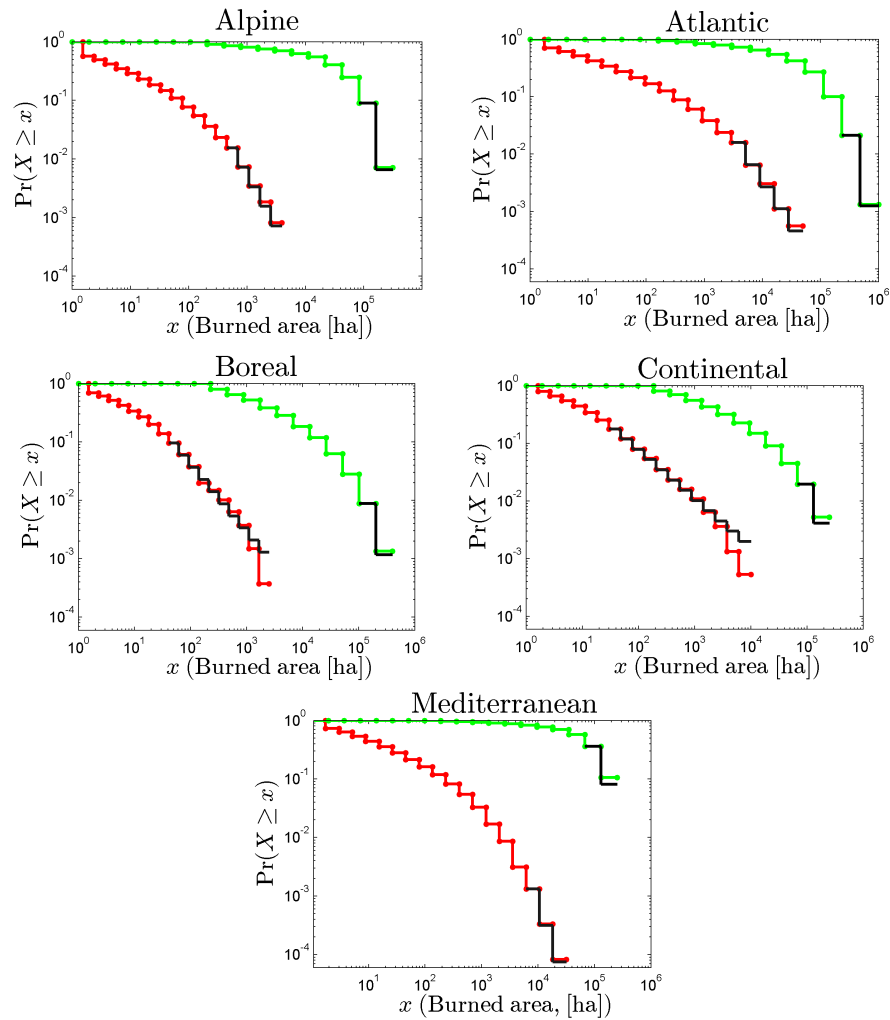

Figure 3. Results of power law fitting for the EFFIS (red lines) and CLM (green lines) data sets for each ecoregion across Europe. In these graphs, the abscissa represents the monthly burned area (in hectares, ha) and the ordinate represents the inverse cumulative distribution function (CDF). Note that both axes are represented in a logarithmic scale.

NPGD

2, 1553-1586, 2015

Power law distributions of wildfires across Europe

B. Di Mauro et al.

\section{Title Page}

\section{Abstract}

Conclusions

Tables

14

$\triangleleft$

Back

\section{Full Screen / Esc}

Printer-friendly Version

Interactive Discussion 

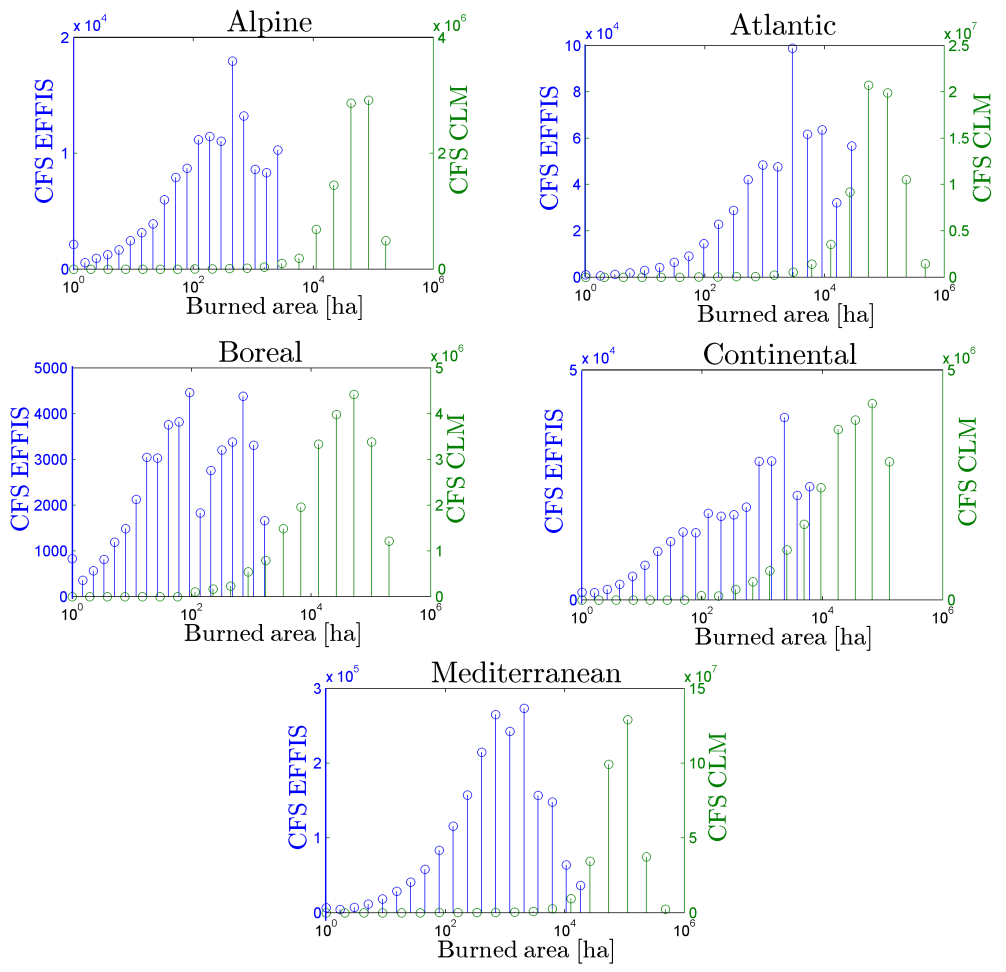

Figure 4. Characteristic Fire Size (CFS) distribution for the EFFIS (blue lines) and for the CLM (green lines) data. Each plot represents a different ecological region in Europe.
NPGD

2, 1553-1586, 2015

\section{Power law distributions of wildfires across Europe}

B. Di Mauro et al.

\section{Title Page}

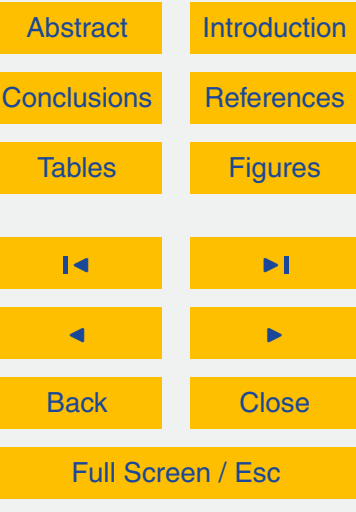

Printer-friendly Version

Interactive Discussion 


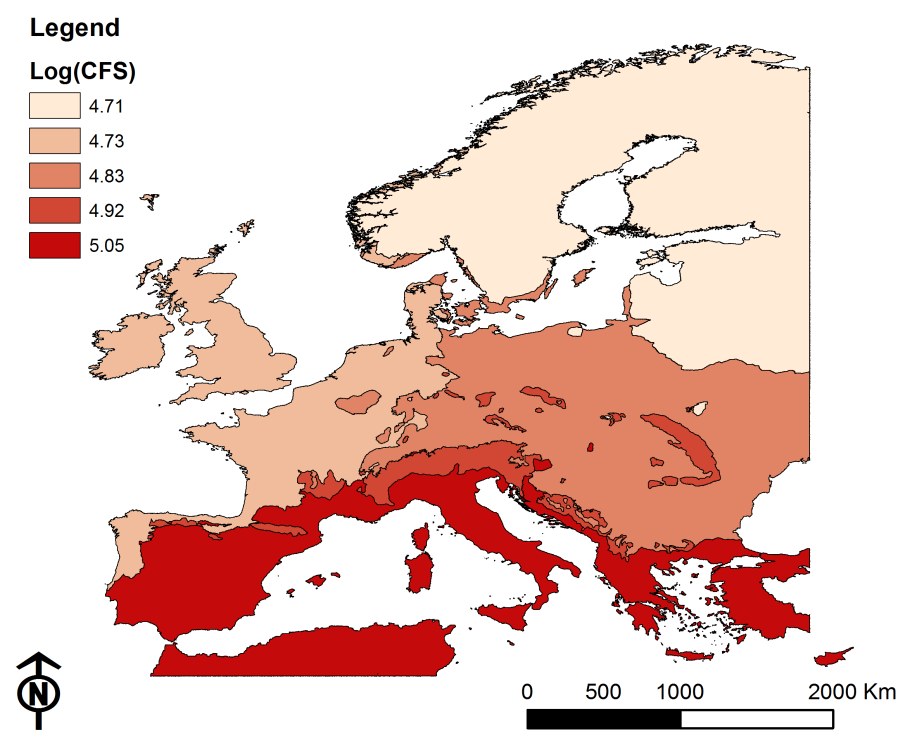

Figure 5. Spatial representation of power law $\alpha$ exponent for the EFFIS data set.

\section{NPGD}

2, 1553-1586, 2015

\section{Power law} distributions of wildfires across Europe

B. Di Mauro et al.

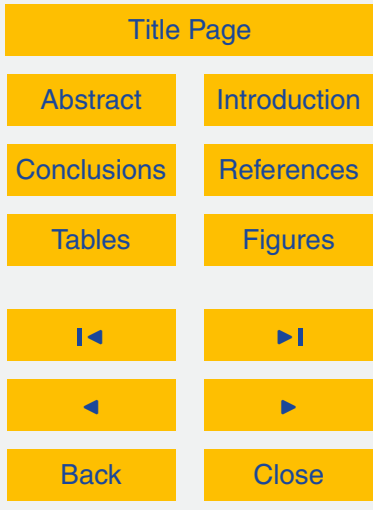

Full Screen / Esc

Printer-friendly Version

Interactive Discussion 


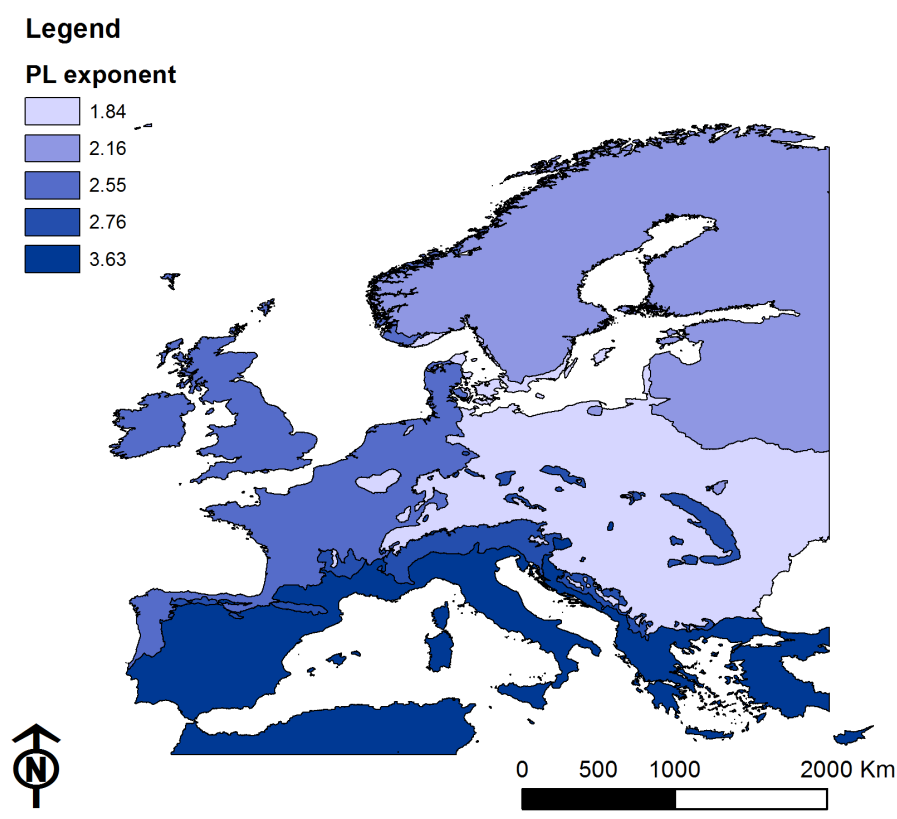

Figure 6. Spatial representation of the Characteristic Fire size (CFS) for the Community Land Model (CLM) burned area simulations

\section{NPGD}

2, 1553-1586, 2015

\section{Power law distributions of wildfires across Europe}

B. Di Mauro et al.

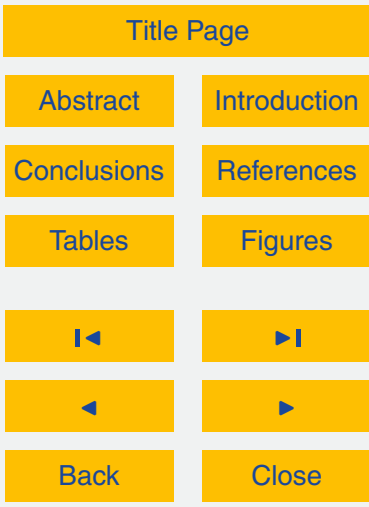

Full Screen / Esc

Printer-friendly Version

Interactive Discussion 